\title{
Saberes e fazeres da gastronomia: diferentes abordagens sobre comida, alimentação.
}

\author{
Roberto do Nascimento e Silva \\ Universidade de Santa Cruz do Sul - UNISC - Santa Cruz do Sul - Rio Grande do Sul - Brasil \\ Mônica Elisa Dias Pons \\ Universidade Federal de Santa Maria - UFSM - Santa Maria - Rio Grande do Sul - Brasil
}

Muito se fala sobre gastronomia, culinária e alimentação em nossos dias, da escola aos almoços em família, dos programas de televisão aos programas governamentais de saúde, dos blogs especializados ao mercado editorial de livros e revistas, o tema parece ter infindáveis abordagens no cotidiano das sociedades contemporâneas. Muito embora exista uma glamourização do comer e do cozinhar - com humor e ironia já foi cunhada a expressão "raio gourmetizador", é um campo da cultura e do conhecimento humanos que faz parte da própria constituição das identidades culturais. Desta forma, compreender esses variados caminhos e abordagens do comer, cozinhar, compartir, nutrir nos quais a tradição e a inovação andam juntas nas discussões do que deve ser preservado nas práticas culinárias como verdadeiro patrimônio cultural e o que pode ser inspirador de invenções gastronômicas não são poucas e, muito pouco, unânimes.

Como todo objeto cultural a comida não é um ato humano imutável, ela transforma-se ao longo do tempo e difere-se no espaço, com permanências longas atravessadas pelos efeitos instantâneos de inovações técnicas, novos insumos, modas gastronômicas e crises de abastecimento. 
O ato de comer é antes de tudo um ato de sobrevivência, ou seja de adaptação ao meio e aos grupos sociais. Assim, os pesquisadores que tem por tarefa desvendar e compreender esse universo da comida e da alimentação precisam de um olhar multidisciplinar e interdisciplinar para melhor acercar-se um objeto tão cotidiano (está em nossas mesas todos os dias) e ao mesmo tempo tão esquivo quando queremos investiga-lo. Por ser imprescindível e corriqueira na maior parte das vezes de nosso dia a dia cada vez mais rápido e impessoal, a alimentação parece tornar-se invisível, padronizada e industrial. Perde-se o lado mais maravilhoso deste, ao mesmo tempo, produto e ritual, das diferentes culturas humanas que é o ato de comer/cozinhar. Talvez esteja aí uma das pistas para entendermos o fenômeno midiático-social da gastronomia, aspiramos, mesmo que na forma de simulacro, a volta ao ritual alimentar, é o desejo da fogueira primeva que assa nossos alimentos e nos reúne em celebração.

Os artigos selecionados, e a tarefa não foi fácil (este dossiê teve um dos maiores afluxos de artigos dos últimos tempos), traduzem os resultados obtidos por meio de projetos de pesquisa e de pesquisadores que fazem parte de uma intensa e já volumosa produção acadêmica, pesquisadores estes que estão comprometidos com a reflexão intelectual sobre os atos de comer, cozinhar, preservar, inventar e narrar os alimentos que produzem a identidade cultural de nossas sociedades.

O artigo que abre este dossiê, intitulado "O saber fazer enogastronômico do território do Vale dos Vinhedos/RS" aborda esta temática a partir da construção do conhecimento numa área que tem o "saber fazer" como práxis de trabalho, ao mesmo tempo em que discute a enogastronomia como um produto territorial oriundo de um tripé que compreende o produtor rural, o alimento e as empresas prestadoras de serviço. Discussão esta, que perpassa pelo conhecimento de enogastronomia como harmonização entre vinho e comida.

A seguir o artigo de nome "Comida, Cultura e Identidade: Conexões a partir do campo da Gastronomia" propõe uma discussão sobre o estado da arte no contexto nacional, apontando questões que julgam pertinentes no 
desenvolvimento de pesquisas sobre gastronomia e alimentação, que apontam como associadas às questões sociais e identitárias.

Logo após temos textos que discutem as culturas gastronômicas locais por diferentes abordagens unidas pela importância das comidas tradicionais na formação das identidades culturais. Faz parte deles o texto intitulado "A Cozinha Gaúcha: um resgate dos sabores e saberes da gastronomia do Rio Grande do Sul", que deriva de um projeto de pesquisa vinculado ao programa RS MAIS GASTRONOMIA da Casa Civil, do Governo do Estado do Rio Grande do Sul, de 2011 a 2015, e teve como objetivo verificar o cenário das tradições gastronômicas dos principais grupos étnicos do estado, tendo como recorte para a pesquisa de campo, a região Centro Sul.

Seguido do artigo "Modos de Vigencia y Resignificación de Comidas Tradicionales en Valles Y Puna de Belén, Catamarca" apresenta uma relevante pesquisa sobre mais de sessenta tipos de preparação tradicionais de alimentos salgados, doces e bebidas no Departamento de Belén, Província de Catamarca (comunidades do Vale, Prepuna e Puna). Para compreender esse universo forma propostas indagações simples e, ao mesmo tempo difíceis, quando um prato é considerado parte da cozinha tradicional? Como passa a pertencer a este repertório? Por que alguns alimentos fazem parte dos repertórios tradicionais e outros não? A partir da pesquisa foi verificado que a maior parte dos alimentos que foram apresentados como tradicionais passaram por um processo de ressignificação e reavaliação, em mais de uma maneira ao longo do tempo.

Já o artigo "Sabores Locais: memórias e narrativas da gastronomia na cidade de Florianópolis/SC", propõe uma discussão a partir das memórias e narrativas de moradores no preparo de pratos tradicionais, como a "tainha escalada" e o "pastel de berbigão", que apresentam uma forte relação com traços da cultura portuguesa e outras influências. Um resgate da culinária como integrante da gastronomia local, sendo considerados bens imateriais representativos de uma determinada cultura. 
$\mathrm{Na}$ sequência, temos $\mathrm{O}$ artigo "A comida em comunidades quilombolas: reflexões sobre saberes e mercados solidários" trata da comida nas comunidades remanescentes de quilombo do Maciço da Pedra Branca (RJ) e suas relações em redes de contato e mercados próximos, resgatando formas de tradicionalidade como diferencial na produção, consumo e trocas de alimentos.

Revelando um pouco da riqueza e complexidade das religiões afro brasileiras, e sua forte relação simbólica com a culinária, o artigo "Nos banquetes de candomblé os deuses comem: representatividade mitológica nas comidas de santo", baseado em resgate de informações baseadas na oralidade, trata sobre as influências mitológicas das comidas de santo, os expressivos banquetes que são oferecidos às divindades do Candomblé e trazem consigo preferências e repugnâncias dos orixás, carregados de signos da interação étnica, reflexos do hibridismo cultural.

O texto "Gastronomia como vetor de desenvolvimento: um resgate histórico no município de São Borja" apresenta como necessário resgatar parte da história da alimentação e do processo cultural gastronômico de um dos municípios mais antigos do Rio Grande do Sul para proporcionar a possibilidade de revivificar a cultura gastronômica e, a partir daí, ter possibilidades de desenvolvimento econômico no setor gastronômico.

O objeto central do texto "A tradição do milho: o ingrediente base da cozinha caipira e das festas juninas" é o insumo principal da culinária caipira, revela que o milho tem um papel central para fortalecer a permanência de valores tradicionais expressos através dos pratos típicos da cozinha paulista.

Também trazendo como objeto central de análise um insumo, o texto “A Inserção da Bananicultura em São Bento do Sapucaí: Práticas Saudáveis e Saberes Gastronômicos na Serra da Mantiqueira", defende que a banana tem enorme potencial para ao longo de seu processo de produção, distribuição e consumo trazer benefícios para a saúde, a alimentação e a gastronomia, a partir de princípios da agricultura orgânica, da pequena propriedade e da slow food. Da mesma forma, o artigo "A influência da ostra 
na origem, formação e manutenção da Via Gastronômica do Ribeirão da Ilha - Rota das Ostras - Florianópolis, SC", investiga como o ingrediente "ostra" está na origem, formação e manutenção de uma rota gastronômica, utiliza-se de entrevistas com os envolvidos na rota, de donos de restaurantes à produtores do molusco, que revelam que apesar de ter a ostra como central na atividade da rota, a atividade é bem mais complexa.

Este dossiê destaca também a relação da gastronomia no contexto da produção capitalista de alimentos (commodities) versus a gastronomia de base familiar (agroindústrias), através do artigo intitulado "Tradição Alimentar: Elemento de Emancipação frente a mecanismos globais de dominação", cujo objetivo é apresentar o espaço rural e as tensões que nele se fazem presente.

Também fazem parte deste número da Revista, na parte de temas livres, os artigos "A perspectiva territorial no planejamento e gestão do Turismo", que ao reconhecer a importância do Turismo no campo econômico brasileiro, traz o conceito de território como operacional no planejamento da atividade turística e potencializador do Turismo como agente do desenvolvimento regional; o artigo "Alimentos em zonas de conflito: perspectivas interdisciplinares", que trata, a partir da análise da obra Food in Zones of Conflict: Cross-Disciplinary Perspectives, das transformações que ocorrem em áreas de conflito, tanto nas formas de acessar, distribuir e produzir alimentos, como nos valores e significados sociais; e, Cultura e Patrimônio: a alimentação e o "savoir-faire"na mercantilização, patrimonialização e outras propostas do turismo e da indústria cultural, artigo este que pretende esboçar aspectos socioculturais de construção da gastronomia, por meio da compreensão do seu poder de atratividade ao considerar um território relevante para a apropriação do turismo cultural no que tange principalmente ao olhar dos que a buscam como arte, prazer à mesa, memória dos lugares e sentimentos, mas também tece uma crítica à indústria da moda dos sabores e almeja por meio de uma revisão bibliográfica a partir dos estudos culturais traçar uma ideia 
de como se encontra a mediação entre a mercantilização e a ideia do patrimônio, entendendo que o gosto pode mudar com a sua globalização.

Está na mesa! Desejamos uma saborosa leitura à todos.

Os organizadores.

Ágora [ISSN 1982-6737]. Santa Cruz do Sul, v. 18, n. 1, p. 1-6, jan./jun. 2016.

http://online.unisc.br/seer/index.php/agora/index 